\title{
The Language Symptom
}

Language skills are no longer a given among well-educated youth. One study, which the Copenhagen Business School (CBS), The University of Copenhagen and 'think tank' Denmark Business Research Academy (DEA) have just published, shows that the latest secondary school reform has reduced the share of student exams with three foreign languages from $41 \%$ of the class of 2007 , to $3 \%$ of the class that graduated in 2009. In practice, this means that from now on, students with high school diplomas only have access to knowledge and international cooperation in Danish and English.

The complete disappearance of earlier generations' proficiency in German, French and Latin in high school in this way, however, creates more room for "chit chat courses", where cultural capital brought from home can be translated as opinions about this and that, and empty phrases in Danish and English are exchanged for good grades. This is then adorned with the term "interdisciplinary" despite the fact that no real subjects are involved. Predictably enough, the opinion of the chairman of the Danish high school student union DGS, is that it is the fault of the language courses, which are not good enough at "selling themselves". They are boring. One just sits there and translates a French text, and afterwards receives the results of the effort, full of faults highlighted in red. Very boring. The implied reference must be, that high school students are apparently not otherwise used to having mistakes in their work corrected. Which, again, suggests that the popular courses, those which can "sell themselves", are so vague in content, that one answer may be just as good as the other. That's how you get "interdisciplinary" success experiences.

Because courses in which one can chit chat one's way out of anything, appear as equal competitors to courses where one is forced to toil, one need not blame courses such as French, German, Spanish and Chinese, that they don't have the same design as the very popular "social studies" course. One could actually, with good reason, ask if "social studies" is really designed, so that it deserves the label "course". Truth be told, how much learning is actually disseminated from those subjects, which are assumed to hide behind the collective heading "social studies"? Law, sociology, national economics, anthropology and political science, presumably.

The social-scientific disciplines mentioned here are all committed to a certain empirical stance, a number of theories and a selection of methods, which in no way can be reduced to the chit chat level, where one answer is just as good as the other. Where these disciplines are taught in a serious manner, one can certainly get an assignment back full of indicated errors. If this does not happen already in high school, then the only possible explanation is that the discipline is misrepresented. This is exactly what is meant by social studies being better than language courses at "selling themselves".

Students cannot know that it is not the language courses there is something wrong with, but it's the "sexy" courses. Foreign languages in high school have, not yet at any rate, let themselves be reduced to dinner conversation, which everyone can follow. But it is sure to come. The authors of the above mentioned report are apparently in complete agreement with the student chairman that, it is about turning the language courses into chit chat courses as soon as possible. One must, as it is said, take a point of departure in the languages as "disseminators of culture", rather than as subjects where one learns to master a language in speech and writing, one could suppose.

If high schools follow these recommendations, it would, in practice, naturally mean that the students should sit and converse about German or French society in Danish, or maybe English? If 
one is not supposed to learn German or French in a way in which some things are wrong and other things correct then such conversations cannot possibly take place in German or French.

The education policy in this country is one massive responsibility waiver. Nobody will take on the responsibility and tell the students what is necessary. In the Danish educational system even the small children have "responsibility for their own learning", and the students in high school can freely opt out of the cumbersome. Logically enough, only an idiot chooses a subject in which actual work has to be done, rather than one, in which it possible to talk oneself out of anything, especially when it comes down to the fact that it is the grade point average that dictates future opportunities. Back in 1979, a social democratic government decided that higher education was a scarce resource, in which access must be limited. That was stupid, but nevertheless, it is apparently still an uncontested idea. Since then, the students have chosen subjects based on level of ease. It is not them that there is anything wrong with.

\section{Anne Knudsen \\ Dr. Phil. - Editor in Chief, Administrative Director Weekendavisen $\mathbf{A} / \mathbf{S}$}

First printed in the influential Danish newspaper "Weekendavisen" on 27th May 2011. Translated by Michael Lambarena.

This article was uploaded to http://www.languageatwork.eu in September of 2011 and published under a "Creative Commons license Attribution Non-commercial No derivatives (cc by-nc-sa)" for more information please go to: http://creativecommons.org/about/license/ 